\title{
USE OF MULTIVARIATE EXPERIMENTAL DESIGNS FOR OPTIMIZING THE REDUCTIVE DEGRADATION OF AN AZO DYE IN THE PRESENCE OF REDOX MEDIATORS
}

Diego R. S. Lima, Bruno E. L. Baeta, Gilmare A. da Silva, Silvana Q. Silva and Sérgio F. Aquino*

Departamento de Química, Universidade Federal de Ouro Preto, Ouro Preto - MG, Brasil

Recebido em 25/10/2013; aceito em 11/02/2014; publicado na web em 08/05/2014

\begin{abstract}
The optimization of the anaerobic degradation of the azo dye Remazol golden yellow RNL was performed according to multivariate experimental designs: a $2^{2}$ full-factorial design and a central composite design (CCD). The CCD revealed that the best incubation conditions (90\% color removal) for the degradation of the azo dye $\left(50 \mathrm{mg} \mathrm{L}^{-1}\right)$ were achieved with $350 \mathrm{mg} \mathrm{L}^{-1}$ of yeast extract and $45 \mathrm{~mL}$ of anaerobic supernatant (free cell extract) produced from the incubation of $650 \mathrm{mg} \mathrm{L}^{-1}$ of anaerobic microorganisms and $250 \mathrm{mg} \mathrm{L}^{-1}$ of glucose. A first-order kinetics model best fit the experimental data $\left(\mathrm{k}=0.0837 \mathrm{~h}^{-1}, \mathrm{R}^{2}=0.9263\right)$.
\end{abstract}

Keywords: azo dye; extracellular degradation; multivariate experimental designs.

\section{INTRODUCTION}

Industrial pollution is one of the primary problems affecting modern society, and the textile industry is amongst the worst polluters. Textile wastewater poses high risks to the environment because of the presence of biodegradable (e.g., starch and surfactants), recalcitrant (e.g., certain dyes), and toxic (e.g., metals and pigments) compounds.

Azo dyes (which contain at least one $-\mathrm{N}=\mathrm{N}-$ bond) represent more than $70 \%(\mathrm{w} / \mathrm{w})$ of the dyes produced worldwide that are used in the textile industry ${ }^{1}$ and are regarded as highly stable and recalcitrant towards aerobic biodegradation. ${ }^{2}$ The primary effects of the discharge of azo dyes into the environment are related to its direct and indirect (through the formation of aromatic amines) toxicity to aquatic organisms and to the coloring of water, which affects photosynthetic organisms. ${ }^{3,4}$

Numerous technologies for textile wastewater treatment have been developed, but biological processes are the most widely used because of their favorable cost-benefit analysis. ${ }^{5}$ Although the aerobic-activated sludge process is very popular in the textile industry, it is not very efficient in removing color from textile effluents. Dye removal in such processes occurs only because of their physical adsorption onto activated sludge, which is periodically discharged. In view of these considerations, different research groups have studied the anaerobic degradation of azo dyes. ${ }^{1,6}$

The anaerobic degradation of azo dye implies the breakage of azo bonds by a co-metabolic reactor, where two reducing equivalents (e.g., $\mathrm{NAD}(\mathrm{P}) \mathrm{H}$ and $\mathrm{FADH}_{2}$ ) donate electrons to the dye, thereby reducing the chromophore system. This process occurs in two steps (equations 1 and 2), and the electron transfer from the donor (the biologically degraded substrate) to the acceptor (the azo dye) is the rate-limiting step in the decolorization kinetics: $:^{7,8}$

$\mathrm{R}_{1}-\mathrm{N}=\mathrm{N}-\mathrm{R}_{2}+2 \mathrm{e}^{-}+2 \mathrm{H}^{+} \rightarrow \mathrm{R}_{1}-\mathrm{NH}-\mathrm{NH}-\mathrm{R}_{2}$ (hydrazo intermediate) (1) $\mathrm{R}_{1}-\mathrm{NH}-\mathrm{NH}-\mathrm{R}_{2}+2 \mathrm{e}^{-}+2 \mathrm{H}^{+} \rightarrow \mathrm{R}_{1}-\mathrm{NH}_{2}+\mathrm{NH}_{2}-\mathrm{R}_{2}$ (aromatic amines) (2)

One strategy employed by some authors ${ }^{9,10}$ to accelerate the electron transfer and increase the removal efficiency of azo dye degradation in anaerobic environments involves the use of redox mediators (RMs) such as riboflavin and quinones. ${ }^{11-13}$ Such RMs exhibit intermediate reduction potentials (Figure 1) and facilitate

*e-mail: sergio@iceb.ufop.br the electron transfer from the substrate (primer donor) to the dye (final acceptor), thereby accelerating the kinetics of decolorization. ${ }^{14}$

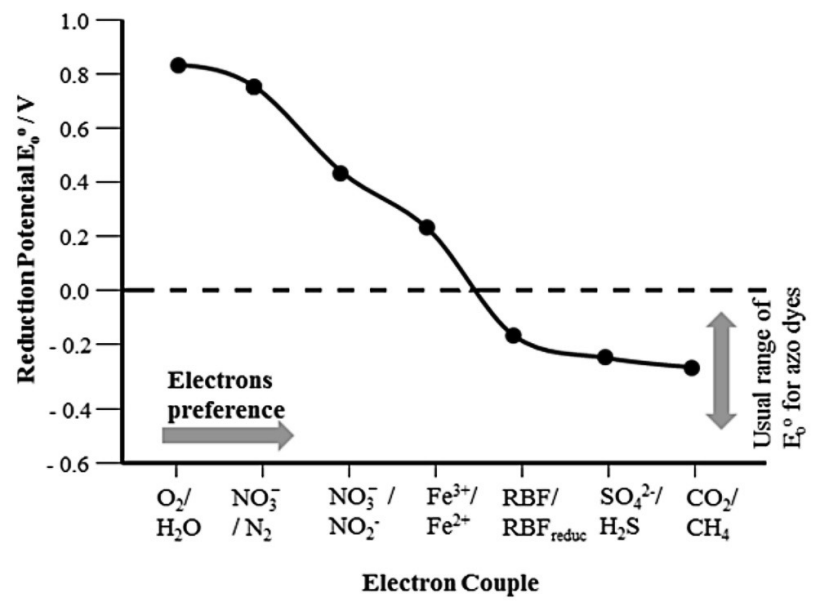

Figure 1. Redox potential for different electron acceptors and preferential electron flux for the biological degradation of organic matter. RBF $=$ Riboflavin. Source: Adapted from ref. 10

RMs are very effective in the reduction of azo dyes because of the unstable nature of the azo bond, which is capable of receiving electrons from reduced flavins and quinones. ${ }^{9}$ The anaerobic degradation of an azo dye in the presence of RM is accomplished in two steps: i) RM reduction by the reducing equivalents produced by substrate metabolism, followed by ii) azo dye reduction by the reduced form of RM (RMreduc). This process is illustrated in Figure 2, which has been adapted from Rau et al. ${ }^{13}$

Anaerobic biotechnology has been widely employed for color and chemical oxygen demand (COD) removal in textile effluents ${ }^{15}$ because of its inherent advantages, which include less sludge (excess microorganisms) production, lower energy input (no aeration is needed), and methane production (potential biofuel). Because biodegradation studies involve numerous variables that can affect the performance of the system, the use of experimental designs and multivariate analysis tools is critical in the optimization of experiments to achieve maximum performance. ${ }^{16,17}$ Because multivariate statistical methods take into account the correlations among variables and samples simultaneously, a greater amount of information can be extracted, thereby 


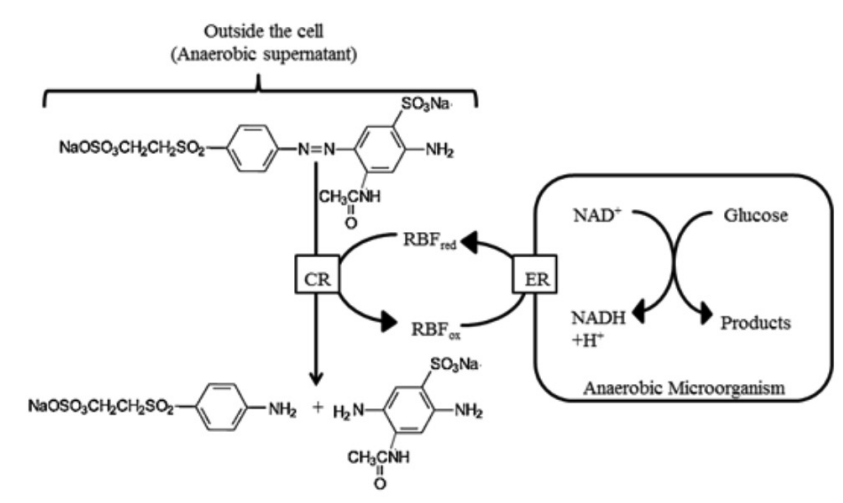

Figure 2. Scheme of anaerobic azo dye (Remazol golden yellow RNL) reduction in the presence of a redox mediator. $R M=$ redox mediator, $E R=$ enzymatic reduction of $R M$, and $C R=$ chemical reduction of azo dye. Adapted from Raul et al. ${ }^{13}$

making the gathered experimental data more valuable.

In this study, we used multivariate experimental designs to determine the best incubation conditions for the anaerobic degradation of the azo dye Remazol golden yellow RNL in the presence of yeast extract as a RM.

\section{EXPERIMENTAL}

\section{Reagents and inoculum}

The sludge (biomass containing anaerobic microorganisms) used as seed (inoculum) in the biodegradation experiments was collected from an upflow anaerobic sludge blanket (UASB) reactor fed with domestic sewage and operated at demonstrative scale at the Centre for Research and Training in Sanitation (CePTS) at the UFMG/ COPASA located near the Arrudas Sewage Treatment Plant, Belo Horizonte, MG.

The glucose used in all of the experiments was $\mathrm{D}(+)$-glucose anhydrous P.A. (Vetec); the yeast extract was purchased from Himedia and contained $50 \mu \mathrm{g} \mathrm{g}^{-1}$ of riboflavin. The azo dye Remazol golden yellow RNL was generously provided by a local textile company and was used without purification or previous hydrolysis.

\section{Screening experimental designs}

A screening procedure was initially performed to determine which variables and the levels of those variables resulted in the best experimental conditions for the decolorization of Remazol golden yellow RNL azo dye solutions. We performed four full-factorial designs at two levels $\left(2^{2}\right)$ with triplicate at the central point, which resulted in the incubation of seven batch reactors (Table 1). According to Montgomery, ${ }^{18}$ the use of a central point in triplicate allows for the addition of a third level for each factor as well as for the quantification of errors associated with individual effects and to interactions amongst variables. The variable effects were calculated at the 0.05 level of significance using the Microsoft Excel spreadsheet software. ${ }^{19}$

The batch reactors consisted of amber glass flasks $(250 \mathrm{~mL})$, which received the solutions indicated in Table 1 before being incubated at an orbital shaker (Scolab) for $48 \mathrm{~h}$ at $25^{\circ} \mathrm{C}$ and $150 \mathrm{rpm}$. The experiments were conducted randomly with the concentration of the Remazol golden yellow RNL azo dye fixed at $50 \mathrm{mg} \mathrm{L}^{-1}$ (estimated on the basis of data provided by the textile company that provided the sample) and using $25 \mathrm{~mL}$ of biomedia, whose composition is described elsewhere. ${ }^{5}$ The molar absorptivity of the Remazol golden yellow RNL was measured as 7,506.7 $\mathrm{mol}^{-1} \mathrm{~L} \mathrm{~cm}^{-1}$. To ensure
Table 1. Variables and experimental conditions used in the screening designs (D). The values in bracket indicate the decoded values

\begin{tabular}{|c|c|c|c|c|c|}
\hline $\begin{array}{l}\text { Experimental } \\
\text { Condition }\end{array}$ & $\begin{array}{c}\text { Micro- } \\
\text { organism } \\
\left(\mathrm{mg} \mathrm{L}^{-1}\right)\end{array}$ & $\begin{array}{l}\text { Glucose } \\
\left(\mathrm{mg} \mathrm{L}^{-1}\right)\end{array}$ & $\begin{array}{c}\text { Yeast } \\
\text { extract } \\
\left(\mathrm{mg} \mathrm{L}^{-1}\right) \\
\end{array}$ & $\begin{array}{l}\text { Supernatant } \\
(45 \mathrm{~mL})\end{array}$ & $\begin{array}{l}\text { Ratio } \\
\text { F/M }\end{array}$ \\
\hline D1- 1 & $-1(500)$ & $-1(100)$ & & & 0.2 \\
\hline D1 - 2 & $-1(500)$ & $+1(500)$ & & & 1.0 \\
\hline D1 -3 & $+1(1000)$ & $-1(100)$ & & & 0.1 \\
\hline D1 - 4 & $+1(1000)$ & $+1(500)$ & & & 0.5 \\
\hline D1 - 5 & $0(750)$ & $0(300)$ & & & 0.4 \\
\hline D1 - 6 & $0(750)$ & $0(300)$ & & & 0.4 \\
\hline D1 -7 & $0(750)$ & $0(300)$ & & & 0.4 \\
\hline $\mathrm{D} 2-1$ & $-1(500)$ & & $1(100)$ & & 0.2 \\
\hline $\mathrm{D} 2-2$ & $1(500)$ & & $+1(500)$ & & 1.0 \\
\hline $\mathrm{D} 2-3$ & $+1(1000)$ & & $-1(100)$ & & 0.1 \\
\hline $\mathrm{D} 2-4$ & $+1(1000)$ & & $+1(500)$ & & 0.5 \\
\hline $\mathrm{D} 2-5$ & $0(750)$ & & $0(300)$ & & 0.4 \\
\hline $\mathrm{D} 2-6$ & $0(750)$ & & $0(300)$ & & 0.4 \\
\hline $\mathrm{D} 2-7$ & $0(750)$ & & $0(300)$ & & 0.4 \\
\hline D3 - 1 & & $-1(100)$ & & ${ }^{2} \mathrm{D} 1-1$ & ${ }^{3} 0.2$ \\
\hline D3 - 2 & & $+1(500)$ & & ${ }^{2} \mathrm{D} 1-2$ & ${ }^{3} 1.0$ \\
\hline D3 - 3 & & $-1(100)$ & & ${ }^{2} \mathrm{D} 1-3$ & ${ }^{3} 0.1$ \\
\hline D3 - 4 & & $+1(500)$ & & ${ }^{2} \mathrm{D} 1-4$ & ${ }^{3} 0.5$ \\
\hline D3 - 5 & & $0(300)$ & & ${ }^{2} \mathrm{D} 1-5$ & ${ }^{3} 0.4$ \\
\hline D3 - 6 & & $0(300)$ & & ${ }^{2} \mathrm{D} 1-6$ & ${ }^{3} 0.4$ \\
\hline D3 - 7 & & $0(300)$ & & ${ }^{2} \mathrm{D} 1-7$ & ${ }^{3} 0.4$ \\
\hline D4 - 1 & & & $-1(100)$ & ${ }^{2} \mathrm{D} 1-1$ & ${ }^{3} 0.2$ \\
\hline D4 - 2 & & & $+1(500)$ & ${ }^{2} \mathrm{D} 1-2$ & ${ }^{3} 1.0$ \\
\hline D4 - 3 & & & $-1(100)$ & ${ }^{2} \mathrm{D} 1-3$ & ${ }^{3} 0.1$ \\
\hline D4 - 4 & & & $+1(500)$ & ${ }^{2} \mathrm{D} 1-4$ & ${ }^{3} 0.5$ \\
\hline $\mathrm{D} 4-5$ & & & $0(300)$ & ${ }^{2} \mathrm{D} 1-5$ & ${ }^{3} 0.4$ \\
\hline D4 - 6 & & & $0(300)$ & ${ }^{2} \mathrm{D} 1-6$ & ${ }^{3} 0.4$ \\
\hline $\mathrm{D} 4-7$ & & & $0(300)$ & ${ }^{2} \mathrm{D} 1-7$ & ${ }^{3} 0.4$ \\
\hline
\end{tabular}

${ }^{1} \mathrm{~F} / \mathrm{M}$ - Food to microorganisms ratio; ${ }^{2}$ Supernatant produced in the same conditions described for experiments D $1 ;^{3}$ Indicates the F/M used to incubate microorganisms and produce anaerobic supernatant.

anaerobic conditions in the batch reactors, nitrogen gas (Praxair, industrial grade 3.0) was gently fluxed onto the headspace of the flasks for 2 min before the reactors were closed with rubber caps and sealed with aluminum crimps, as described by Baeta et $a l .^{20}$

The concentration of azo dye in the bulk solution was estimated from its absorbance, which was measured at a wavelength of $410 \mathrm{~nm}$ using a spectrophotometer (Biospectro, SP-220), which was the maximum absorbance wavelength for the azo dye. The efficiency of color removal was calculated in each flask according to the absorbance of centrifuged samples ( $5000 \mathrm{rpm}$ for $20 \mathrm{~min}$ ) collected at the beginning $\left(\mathrm{t}_{0 \mathrm{~h}}\right)$ and the end $\left(\mathrm{t}_{48 \mathrm{~h}}\right)$ of each experiment.

Notably, with respect to the four experiments depicted in Table 1, experiment 1 (D1) was designed to verify the efficiency of color removal in the absence of a redox mediator and in the presence of glucose as the sole carbon and energy source, whereas experiment 2 (D2) was intended to assess color removal in the presence of yeast extract as a source of both a redox mediator (riboflavin) and carbon/energy. In experiments 3 and 4 (D3 and D4), the batch reactors were incubated under the same conditions described for D1 and D2, respectively, except that the anaerobic biomass in D1 and D2 was replaced by anaerobic supernatant in D3 and D4. Consequently, the experiments D3 and D4 were designed to assess the abiotic color removal in the presence of free cell extracts (anaerobic supernatant) that contained reduced compounds previously produced by anaerobic microorganisms. 
For the production of the anaerobic supernatant (free cell extract), amber glass flasks were incubated $\left(25^{\circ} \mathrm{C}\right.$ and $\left.150 \mathrm{rpm}\right)$ with glucose and anaerobic biomass under the conditions detailed in Table 1. After $24 \mathrm{~h}$ of incubation, the contents of the flasks were carefully transferred to $50-\mathrm{mL}$ plastic centrifuge tubes (Falcon) under a gentle flux of nitrogen (as previously described) and capped for centrifugation at $5000 \mathrm{rpm}$ for $20 \mathrm{~min}$. The resulting supernatant (free cell extract) was then used $(45 \mathrm{~mL})$ for incubation of the D3 and D4 batch reactors.

\section{Central composite design}

A spherical central composite multivariate design was conducted to optimize the experimental conditions for color removal determined during the screening step. The variables chosen were, as indicated by the full $2^{2}$ factorial designs, i) the yeast extract concentration, ii) the glucose concentration, and iii) the anaerobic microorganism concentration. The concentrations used in each experiment and their respective decoded values are shown in Table 2.

As described before for the screening designs, the residual concentration of Remazol golden yellow RNL was measured at the beginning $\left(\mathrm{t}_{0 \mathrm{~h}}\right)$ and end $\left(\mathrm{t}_{48 \mathrm{~h}}\right)$ of each experiment for correlation with the process variables. The effects of the variables were calculated, and a multiple linear regression model was constructed a level of significance of 0.05 using the Microsoft Excel software. ${ }^{19}$

Table 2. Incubation conditions and coded values used in the spherical central composite design. The values in bracket indicate the decoded values

\begin{tabular}{cccc}
\hline Experiment & $\begin{array}{c}\text { Yeast extract } \\
\left(\mathrm{mg} \mathrm{L}^{-1}\right)\end{array}$ & $\begin{array}{c}\text { Glucose } \\
\left(\mathrm{mg} \mathrm{L}^{-1}\right)\end{array}$ & $\begin{array}{c}\text { Microorganism } \\
\left(\mathrm{mg} \mathrm{L}^{-1}\right)\end{array}$ \\
\hline 1 & $-1(250)$ & $-1(250)$ & $-1(650)$ \\
2 & $-1(250)$ & $-1(250)$ & $1(800)$ \\
3 & $-1(250)$ & $1(350)$ & $-1(650)$ \\
4 & $-1(250)$ & $1(350)$ & $1(800)$ \\
5 & $1(350)$ & $-1(250)$ & $-1(650)$ \\
6 & $1(350)$ & $-1(250)$ & $1(800)$ \\
7 & $1(350)$ & $1(350)$ & $-1(650)$ \\
8 & $1(350)$ & $1(350)$ & $1(800)$ \\
9 & $0(300)$ & $0(300)$ & $-1.68(598.87)$ \\
10 & $0(300)$ & $0(300)$ & $1.68(851.13)$ \\
11 & $0(300)$ & $-1.68(215.91)$ & $0(725)$ \\
12 & $0(300)$ & $1.68(384.09)$ & $0(725)$ \\
13 & $-1.68(215.91)$ & $0(300)$ & $0(725)$ \\
14 & $1.68(384.09)$ & $0(300)$ & $0(725)$ \\
$15^{1}$ & $0(300)$ & $0(300)$ & $0(725)$ \\
\hline
\end{tabular}

${ }^{1}$ The central point was run in quintuplicate.

\section{Assessment of color removal by adsorption and chemical reduction}

To estimate the removal of the azo dye via its adsorption onto anaerobic sludge, an experiment with inactive biomass was devised for the same experimental conditions depicted in Table 1 for experiment D1-1. In this experiment, amber glass flasks were incubated with autoclaved $\left(120^{\circ} \mathrm{C}\right.$ for $\left.15 \mathrm{~min}\right)$ anaerobic sludge in the presence of nutrient solution $(25 \mathrm{~mL})$ and Remazol golden yellow RNL (50 $\mathrm{mg} \mathrm{L}^{-1}$ ). The experiment was performed in triplicate, and color removal was evaluated on the basis of the absorbance readings taken with centrifuged ( $5000 \mathrm{rpm}$ for $20 \mathrm{~min}$ ) samples collected at the beginning $\left(\mathrm{t}_{0 \mathrm{~h}}\right)$ and end $\left(\mathrm{t}_{48 \mathrm{~h}}\right)$ of the experiment.

To assess the capability of yeast extract in directly reducing the azo dye, we devised another experiment in which triplicate flasks were incubated with nutrient solution $(25 \mathrm{~mL})$, Remazol golden yellow RNL (50 $\left.\mathrm{mg} \mathrm{L}^{-1}\right)$ and yeast extract $\left(350 \mathrm{mg} \mathrm{L}^{-1}\right)$ in the absence of anaerobic biomass. Similar to the other experiments, color removal was assessed on the basis of the initial and final absorbance of the centrifuged samples.

\section{Kinetics of Remazol golden yellow RNL degradation}

Kinetic data regarding the degradation of Remazol golden yellow RNL in the presence (assay 1) and absence (assay 2) of anaerobic supernatant was gathered from batch tests. Assay 1 was conducted under the best incubation conditions determined by the spherical central composite design. Assay 2 was conducted as described for assay 1 , but without the addition of the anaerobic supernatant; in this case, the supernatant was replaced by nutrient solution. In both assays, the flasks were incubated as previously described $\left(25^{\circ} \mathrm{C}\right.$ and $150 \mathrm{rpm}$ ) for $60 \mathrm{~h}$, during which time the samples were collected at regular intervals for absorbance readings after being centrifuged.

\section{RESULTS AND DISCUSSION}

Figure 3 shows the results of all four screening design experiments. The results show that in the presence of anaerobic microorganisms, the color removal efficiency varied from $35 \%$ to $75 \%$ when glucose was used as the sole source of carbon and energy (design 1) and from $45 \%$ to $90 \%$ when yeast extract was used instead.

These results confirm the results reported by other authors, ${ }^{5,20}$ who showed that the addition of yeast extract enhanced anaerobic degradation of azo dyes in anaerobic reactors, probably because it acted simultaneously as a source of carbon and riboflavin, which is a well-known redox mediator. ${ }^{21,22}$ Indeed, yeast extract is largely used as source of vitamins in culture biomedia to boost the culture conditions and enhance microorganism activity. ${ }^{23}$

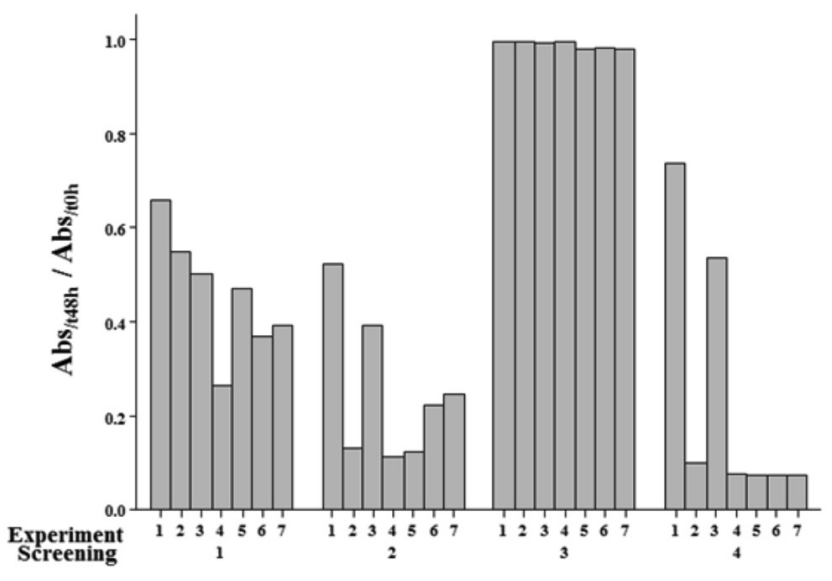

Figure 3. Comparison of solution residual color $\left(A b s_{t 48 h} / A b s_{t 0 h}\right)$ among the 28 screening experiments planned according to Table 1

Riboflavin is a precursor of important coenzymes (e.g., FAD, FMN) that participate in the cellular electron transport chain and is the source of many flavins that act catalyze important cellular reactions such as those involving DNA repair. ${ }^{24}$ Because the azo dye was also significantly removed in the absence of anaerobic microorganisms (D4), the enhancement of cell growth by the addition of yeast extract cannot solely explain the greater color removal. 
Notably, the observed decolorization was mostly attributable to azo dye reductive degradation because the adsorption experiments performed with autoclaved biomass indicated that a maximum of $17 \pm 3 \%$ of Remazol golden yellow RNL could be adsorbed onto biomass over a period of $48 \mathrm{~h}$.

Figure 3 also shows that the use of glucose as a carbon source in the absence of anaerobic microorganisms (Design 3) led to negligible color removal $(<3 \%)$, which implies that the azo dye Remazol golden yellow RNL was not chemically oxidized or reduced by the constituents of the anaerobic supernatant. However, the addition of yeast extract together with the anaerobic supernatant (D4) led to the greatest color removal efficiencies.

The absorbance data gathered during the D4 experiments indicate that an average color removal of $93 \%$ was achieved in the batch reactors incubated with free cell extracts (anaerobic supernatant) and yeast extract, whereas the color removal was only $15 \%$ when only the yeast extract was present (Figure 3). These results clearly indicate that the yeast extract does not contain compounds that can significantly react and transform the azo dye Remazol golden yellow RNL.

Figure 3 shows that the greatest decolorization was observed when anaerobic supernatant and yeast extract were simultaneously present in the flasks containing the azo dye Remazol golden yellow RNL. It also shows that in the absence of microorganisms (D3 and D4), the average color removal was greater compared to those experiments in which the flasks were incubated with anaerobic microorganisms. We hypothesize that the riboflavin present in the yeast extract accelerated the electron transfer from the reducing compounds present in the anaerobic supernatant to the azo dye, as suggested in Figure 2. This hypothesis implies a chemical reduction of the azo dye at the bulk solution, which would depend only on the supernatant-not on the presence of anaerobic cells.

This hypothesis is consistent with the redox potentials of riboflavin (estimated to be $-0.20 \mathrm{~V}$ ) and cellular cofactors (NAD $+=-0.33$ $\mathrm{V}$; FAD $=-0.25 \mathrm{~V})^{13}$ because riboflavin would be preferentially reduced by the cellular cofactors, which would, in turn, reduce the azo dye, which normally has a redox potential in the range of -0.09 $\mathrm{V}$ to $0.46 \mathrm{~V} .^{10,25}$

After screening the experimental designs, we determined the best incubation conditions for the degradation of Remazol golden yellow RNL using a response surface graph, which we plotted using data from the spherical central composite multivariate design.

Table 3 shows data for the $\mathrm{Abs}_{\mathrm{t} 48 \mathrm{~h}} / \mathrm{Abs}_{\mathrm{t} 0 \mathrm{~h}}$ ratios gathered during the experiments performed according to the spherical central composite design. The effects calculated on the basis of these values were significant for all of the evaluated experimental variables, including all interactions and second-order variables, with both the pure error (experimental error) and the quadratic sum of the residues (model error) considered. The central-point replicate values (Table 3) also show that the experiment was highly precise. In addition, the same significance was attributed to all of the variables, independent of the error considered, thereby supporting our hypothesis that the produced quadratic model was valid.

Figure 4 shows the response surface obtained by fixing the variable yeast extract at a concentration of $300 \mathrm{mg} \mathrm{L}^{-1}$ (zero level). Figure 4 indicates that the lowest $\mathrm{Abs}_{\mathrm{t} 48 \mathrm{~h}} / \mathrm{Abs}_{\mathrm{toh}}$ ratio (i.e., the highest removal efficiency) was obtained when the batch reactors were incubated with $300 \mathrm{mg} \mathrm{L}^{-1}$ of yeast extract and $45 \mathrm{~mL}$ of anaerobic supernatant 16 ; this supernatant was produced from the incubation of $650 \mathrm{mg} \mathrm{L}^{-1}$ of biomass in the presence of $250 \mathrm{mg} \mathrm{L}^{-1}$ of glucose, resulting in a food-to-microorganism (F/M) ratio of 0.38 .

We validated the model used to generate Figure 4 by estimating the experimental variance. ${ }^{26}$ An evaluation of the fitness to a quadratic regression model was performed by the ANOVA test, as presented in
Table 3. Measured data of Abst $48 \mathrm{~h} / \mathrm{Abst} 0 \mathrm{~h}$ ratio obtained from the spherical central composite design experiments with the aim to optimize the incubation conditions for Remazol Golden Yellow RNL degradation

\begin{tabular}{cc}
\hline Experiment & $\mathrm{Abs}_{/ 48 \mathrm{~h}} / \mathrm{Abs}_{/ 0 \mathrm{~h}}$ \\
\hline 1 & 0.1420 \\
3 & 0.1708 \\
4 & 0.1412 \\
5 & 0.1167 \\
6 & 0.1001 \\
7 & 0.1503 \\
8 & 0.1869 \\
9 & 0.2139 \\
10 & 0.1200 \\
11 & 0.1485 \\
12 & 0.1250 \\
13 & 0.1766 \\
14 & 0.1612 \\
15 & 0.1900 \\
16 & 0.1890 \\
17 & 0.1867 \\
18 & 0.1850 \\
19 & 0.1863 \\
\hline
\end{tabular}

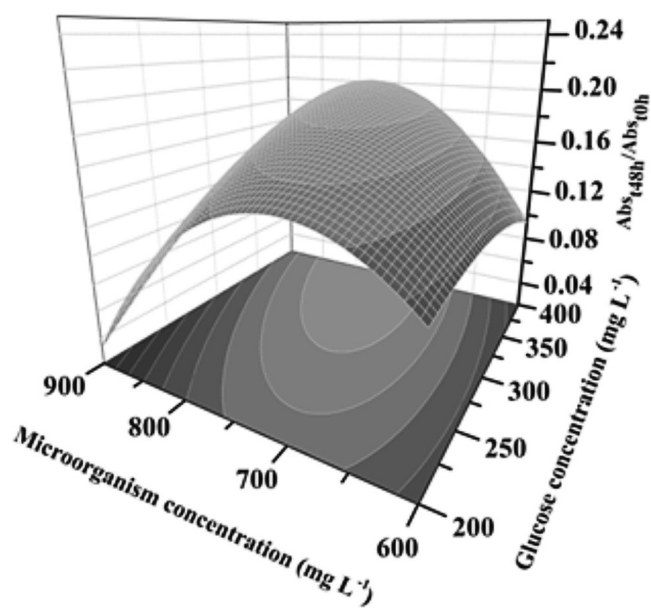

Figure 4. Response surface obtained from the data of the spherical central composite multivariate design and with the variable yeast extract fixed

Table 4, which shows that the regression was statistically significant (SG); in other words, it was possible to correlate the experimental data with the investigated variables. Although the lack of fit was statistically significant, the model was considered acceptable because of the high linear regression coefficient $\left(R^{2}=0.9897\right)$ obtained through comparison of the estimated and measured values. Furthermore, the residuals were small, well spread, and followed a random distribution, which leads to the conclusion that the model is appropriate.

\section{Kinetic model for anaerobic azo dye degradation}

Data related to the degradation of Remazol yellow golden RNL in both the presence and absence of anaerobic microorganisms is 
Table 4. Evaluation of the fitness to quadratic model (level of significance of 0.05) of data from spherical central composite design experiments with the aim to optimize incubation conditions for Remazol Golden Yellow RNL degradation

\begin{tabular}{|c|c|c|c|c|c|c|}
\hline FVSV & QSSQ & $\mathrm{nDF}$ & MS & Fcalc. & Condition & Dist. $F p$ value \\
\hline Regression & $1.7469 \times 10^{-02}$ & 9 & $1.9410 \times 10^{-03}$ & \multirow[t]{2}{*}{95.998} & \multirow[t]{2}{*}{ SG } & \multirow[t]{2}{*}{$7.3742 \times 10^{-08}$} \\
\hline Residues & $1.8197 \times 10^{-04}$ & 9 & $2.0219 \times 10^{-05}$ & & & \\
\hline Lack of fit & $1.7348 \times 10^{-04}$ & 5 & $3.4696 \times 10^{-05}$ & \multirow[t]{2}{*}{16.343} & \multirow[t]{2}{*}{ SG } & \multirow[t]{2}{*}{$9.0870 \times 10^{-03}$} \\
\hline Pure error & $8.4920 \times 10^{-06}$ & 4 & $2.1230 \times 10^{-06}$ & & & \\
\hline Total & $1.7651 \times 10^{-02}$ & 18 & & & & \\
\hline$\%$ explained & & & & 98.97 & & \\
\hline
\end{tabular}

$\mathrm{SV}=$ Source of variance; $\mathrm{SQ}=$ Sum of squares; $\mathrm{nDF}=$ Number of degree of freedom; $\mathrm{MS}=$ Mean square; $\mathrm{F}$ calc $=\mathrm{F}$ measured $; \mathrm{SG}=$ Significant.

presented in Figure 5. As evident in the figure, the decolorization of the azo dye in the absence of anaerobic biomass was faster in the presence of both yeast extract and anaerobic supernatant. Thus, the data confirmed that azo dye degradation is effective when the anaerobic supernatant (free cell extracts) is present, as long as a redox mediator is also present.

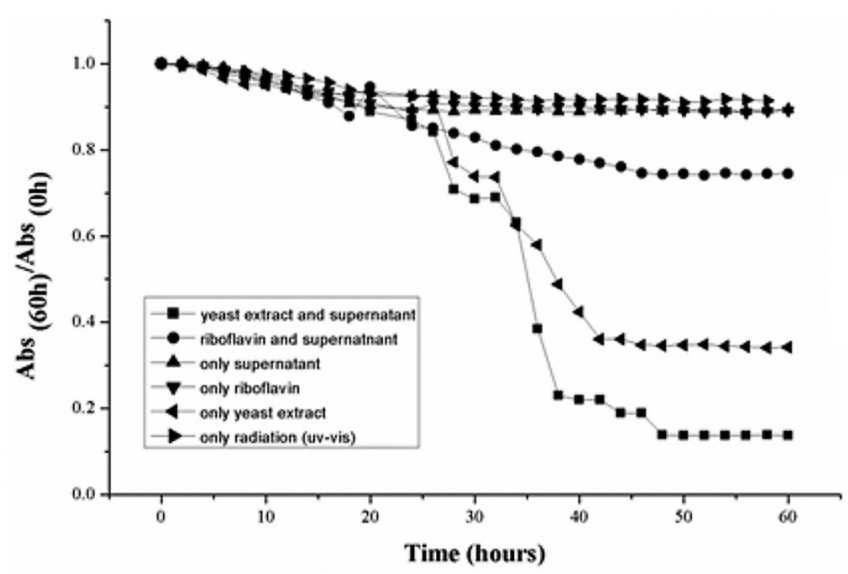

Figure 5. Remazol golden yellow RNL extracellular degradation with yeast extract in the presence and absence of the anaerobic supernatant (free cell extract)

Data analysis indicated that the first-order model best fit the experimental data $\left(\mathrm{K}=0.0837 \mathrm{~h}^{-1}\right.$ and $\left.\mathrm{R}^{2}=0.9263\right)$. This result implies that the extracellular azo dye degradation depended on the residual azo dye concentration and that the presence of redox mediators probably facilitated electron transfer for azo dye reduction. The results presented here are similar to those published in the literature regarding the degradation of azo dyes by anaerobic microorganisms. ${ }^{27-32}$ Figure 6 shows that the azo dye degradation in the proposed system (yeast extract and supernatant) was high because the absorbance of the treated solution was much lower compared to that of the feed solution.

In view of the data presented here, a technological option for the treatment of textile wastewater containing azo dyes could be based on a combined process, as depicted in Figure 7. In such a process, an anaerobic reactor would be fed with domestic sewage and "starching wastewater," which would contain biodegradable materials (e.g., starch, carbohydrates, proteins, and/or lipids). The produced anaerobic supernatant containing reduced compounds could then be complemented with a source of yeast extract (e.g., beer industry wastewater) and mixed with the textile effluent from the dyeing step to degrade the azo dye and remove its color.

The process proposed in this work (Figure 7) offers some advantages compared to other treatment systems, such as the widespread aerobic process known as "activated sludge." Such processes usually

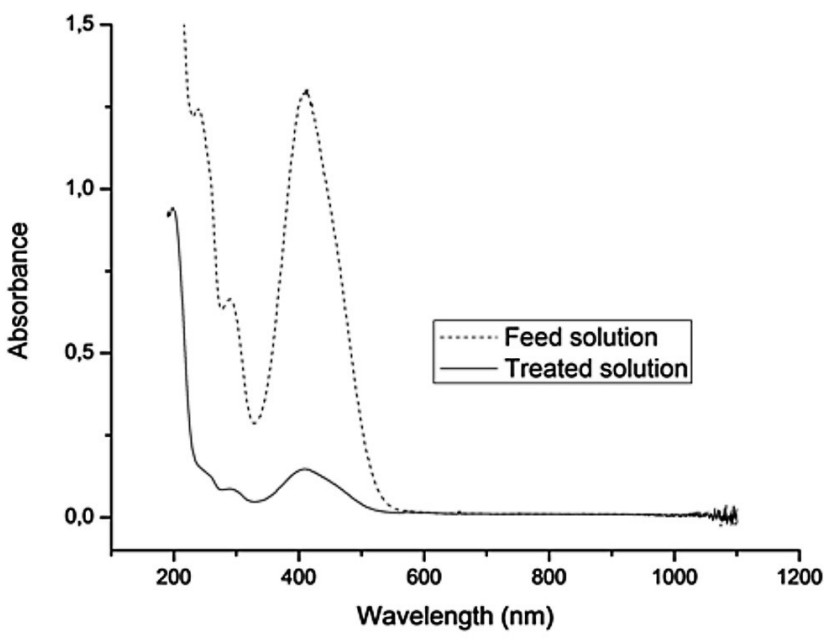

Figure 6. Absorbance spectrum of the feed and treated solutions

lead to poor color removal and expensive operational costs because of the need for continuous aeration and excessive sludge production. One option for decreasing the limitation of this technology is to combine the anaerobic and aerobic systems, as depicted in Figure 7. In this combined system, color removal would occur in the absence of anaerobic microorganisms in the contact tank, which would receive a supernatant produced in the anaerobic reactor and a source of redox mediator (e.g., yeast extract from the fermentation industry). Such a configuration might be capable of decreasing the toxicity toward anaerobic microorganisms and thereby improve reactor performance and achieve greater removal of organic matter. The aerobic reactor installed after the contact tank would, in turn, be primarily responsible for removing the aromatic amines generated during azo dye degradation as well as the residual organic matter (e.g., soluble yeast extract and microbial products from the anaerobic step). This system would consume less oxygen compared to traditional activated sludge technology and probably result in greater color removal rates.

\section{CONCLUSIONS}

The screening of experimental designs allowed us to identify the main variables affecting the degradation of Remazol golden yellow RNL under anaerobic conditions in the presence and absence of microorganisms. The experiments showed that the greatest color removal efficiencies were obtained in the presence of both yeast extract (as a source of the redox mediator riboflavin) and an anaerobic supernatant, which was produced by the anaerobic degradation of glucose. These results showed that direct contact between the anaerobic biomass and the azo dye was not necessary to achieve high color removal and that an efficient degree of decolorization could be obtained as long as the 


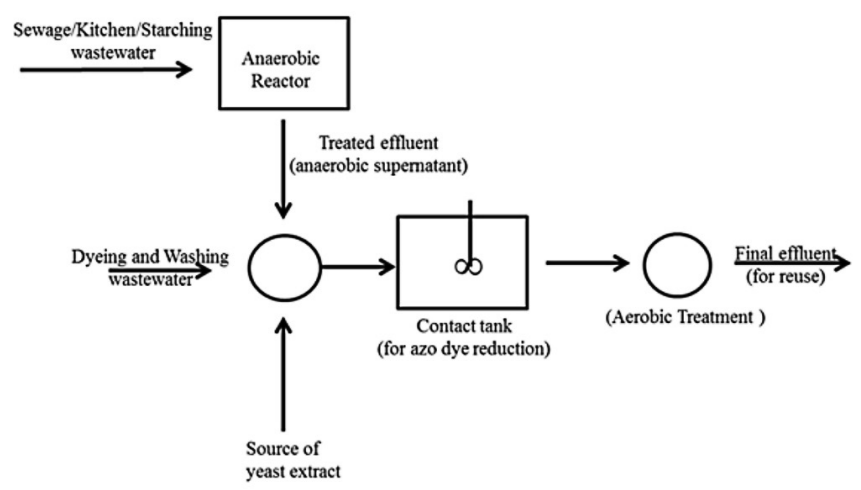

Figure 7. Scheme of a two-step process for the extracellular degradation of azo dyes in the presence of the anaerobic supernatant and the yeast extract

anaerobic supernatant was simultaneously added with yeast extract, thereby strengthening our hypothesis that the anaerobic decolorization of azo dyes is an extracellular process.

The spherical central composite design showed that the greatest color removal (efficiency of $\sim 90 \%$ ) was achieved when the Remazol golden yellow RNL was incubated with $350 \mathrm{mg} \mathrm{L}^{-1}$ of yeast extract in the presence of anaerobic supernatant that was previously produced by anaerobic microorganisms $\left(650 \mathrm{mg} \mathrm{L}^{-1}\right)$ incubated with $250 \mathrm{mg} \mathrm{L}^{-1}$ of glucose. The kinetics of Remazol golden yellow RNL degradation under such optimized conditions showed that a first-order model best fit the experimental data and resulted in a rate constant $(\mathrm{k})$ of 0.0837 $\mathrm{h}^{-1}$. Such results suggest that the decolorization rate depends on the residual azo dye concentration. Collectively, these results suggest that the use of a two-step process (a bioreactor for the production of anaerobic supernatant followed by an abiotic process for the extracellular azo dye reduction) for the treatment of textile effluents is possible.

\section{ACKNOWLEDGMENTS}

The authors would like to acknowledge the financial support received from the Brazilian agencies CNPq, FAPEMIG, and CAPES, as well as that from UFOP.

\section{REFERENCES}

1. Cervantes, F. J.; Dos Santos, A. B.; Environ. Sci. Biotechnol. 2011, 10, 125.

2. Kaushik, P.; Malik, A.; Environ. Int. 2009, 35, 127.

3. Nam, S.; Renganathan, V.; Tratnyek, P. G.; Chemosphere 2001, 45, 59.

4. Pinheiro, H. M.; Touraud, E.; Thomas, O.; Dyes Pigm. 2004, 61, 121.

5. Correa, C. A. R.; Aquino, S. F.; Caldas, P. C. P.; Silva, S. Q.; Eng. Sanit. Ambient. 2009, 14, 559.
6. Van der Zee, F. P.; Lettinga, G.; Field, J. A.; Chemosphere 2001, 44, 1169.

7. Beydilli, M. I.; Pavlostathis, S. G.; Tincher, W. C.; Water Sci. Technol. 1998, 38, 225.

8. Bromley-Challenor, K. C. A.; Knapp, J. S.; Zhang, Z.; Gray, N. C. C.; Hetheridge, M. J.; Evans, M. R.; Water Res. 2000, 34, 4410.

9. Cervantes, F. J.; Van Der Zee, F. P.; Lettinga, G.; Field, J. A.; Water Sci. Technol. 2001, 44, 123.

10. Dos Santos, A. B.; Cervantes, F. J.; Van Lier, J. B.; Eng. Sanit. Ambient. 2007, 12, 102.

11. Semdé, R.; Pierre, D.; Geuskens, G.; Devleeschouwer, M.; Moes A. J.; Int. J. Pharm. 1998, 161, 45.

12. Cervantes, F. J.; Van der Velde, S.; Lettinga, G.; Field, J. A.; FEMS Microbiol. Ecol. 2000, 34, 161.

13. Raul, J.; Knackmuss, H. J.; Stolz, A.; Environ. Sci. Technol. 2002, 36, 1497.

14. Stolz, A.; Appl. Microbiol. Biotechnol. 2001, 56, 69.

15. Ahn, Y.; Kyung-Sok, M.; Speece, R. E.; Water Res. 2001, 35, 4267.

16. Da Silva, G. A.; Augusto, F.; Poppi, R. J.; J. Chromatogr. A 2007, 1138, 251.

17. Barros Neto, B.; Scarminio, I. S.; Bruns, R. E.; Como Fazer Experimentos, Ed. da Unicamp: Campinas, 2003.

18. Montgomery, D. C.; Runger, G. C.; Applied Statistics and Probability for Engineers, John Wiley \& Sons, Inc.: New York, 1991.

19. Teófilo, R. F.; Ferreira, M. M. C.; Quim. Nova 2006, 29, 338.

20. Baêta, B. E. L.; Aquino, S. F.; Silva, S. Q.; Rabelo, C. A.; Biodegradation 2012, 23, 199.

21. Dos Santos, A. B.; Cervantes, F. J.; Van Lier, J. B.; Water Sci. Technol. 2006, 54, 151.

22. Nigam, P.; Banat, I. M.; Singh, D.; Marchant, R.; Process Biochem. 1995, 31, 435.

23. Souza, A. C. S.; Ferreira, C. V.; Jucá, M. B.; Aoyama, H.; Cavagis, A. D. M.; Peppelenbosch, M. P.; Quim. Nova 2005, 28, 887.

24. Massey, V.; Biochem. Soc. Trans. 2000, 28, 283.

25. Bruns, R. E.; Neto, B. B.; Scarmínio, I. S. Como fazer experimentos. Editora da Unicamp: Campinas, 2001.

26. Van der Zee, F. P.; Bouwman, R. H. M.; Strik, D. P. B. T. B.; Letinga, G.; Field, J. A.; Biotechnol. Bioeng. 2001, 75, 691.

27. Karatas, M.; Dursun, S.; Argun, M. E.; J. Biotechnol. 2009, 8, 6856.

28. Sponza, D. T.; Isik, M.; Enzyme Microb. Technol. 2004, 34, 147.

29. Dos Santos, A. B.; Madrid, M. P.; Stams, A. J. M.; Van Lier, J. B.; Cervantes, F. J.; Biotechnol. Progr. 2005, 21, 1140.

30. Annuar, M. S. M.; Adnan, S.; Vikineswary, S.; Water Air Soil Pollut, 2009, 202, 179.

31. Van Der Zee, F. P.; Villaverde, S.; Water Res. 2005, 39, 1425.

32. Pandey, A.; Singh, P.; Iyengar, L.; Int. Biodeterior. Biodegrad. 2007, 59, 73. 